Keywords: Barrett's oesophagus; intestinal metaplasia; oesophageal adenocarcinoma; progression; MIC-1; GDF15; prognostic biomarker

\title{
MIC-1/GDF15 in Barrett's oesophagus and oesophageal adenocarcinoma
}

\begin{abstract}
O M Fisher ${ }^{1}$, A J Levert-Mignon ${ }^{1}$, S J Lord ${ }^{1,2,3}, \mathrm{~K} \mathrm{~K} \mathrm{M} \mathrm{Lee-Ng}^{1}$, N K Botelho ${ }^{1}$, D Falkenback ${ }^{1,4}$, M L Thomas ${ }^{1}$, Y V Bobryshev ${ }^{1,5}$, D C Whiteman ${ }^{6}$, D A Brown ${ }^{1,7}$, S N Breit ${ }^{1}$ and R V Lord ${ }^{\star}, 1,8$

${ }^{1}$ St Vincent's Centre for Applied Medical Research and University of New South Wales, Sydney, NSW 2010 Australia; ${ }^{2}$ NHMRC Clinical Trials Centre University of Sydney, Sydney, NSW 2050, Australia; ${ }^{3}$ Department of Epidemiology and Medical Statistics, School of Medicine, University of Notre Dame, Sydney, NSW 2010 Australia; ${ }^{4}$ Department of Surgery, Lund University Hospital (Skåne University Hospital) and Lund University, Lund 221 85, Sweden; ${ }^{5}$ Faculty of Medicine, School of Medical Sciences, University of New South Wales, Sydney, Australia; ${ }^{6}$ QIMR Berghofer Medical Research Institute, Brisbane, Australia; ${ }^{7}$ Peter Duncan Neuroscience Research Unit, St Vincent's Centre for Applied Medical Research, Sydney, NSW 2010 Australia and ${ }^{8}$ Department of Surgery, School of Medicine, University of Notre Dame, Sydney, NSW 2010 Australia
\end{abstract}

Background: Biomarkers are needed to improve current diagnosis and surveillance strategies for patients with Barrett's oesophagus (BO) and oesophageal adenocarcinoma (OAC). Macrophage inhibitory cytokine 1/growth differentiation factor 15 (MIC-1/GDF15) tissue and plasma levels have been shown to predict disease progression in other cancer types and was therefore evaluated in BO/OAC.

Methods: One hundred thirty-eight patients were studied: 45 normal oesophagus (NE), 37 BO, 16 BO with low-grade dysplasia (LGD) and 40 OAC.

Results: Median tissue expression of MIC-1/GDF15 mRNA was $\geqslant 25$-fold higher in BO and LGD compared to NE $(P<0.001)$; twofold higher in OAC vs BO ( $P=0.039)$; and 47-fold higher in OAC vs NE $(P<0.001)$. Relative MIC-1/GDF15 tissue expression $>720$ discriminated between the presence of either OAC or LGD vs NE with $94 \%$ sensitivity and $71 \%$ specificity (ROC AUC $0.86,95 \% \mathrm{Cl}$ 0.73-0.96; $P<0.001$ ). Macrophage inhibitory cytokine 1/growth differentiation factor 15 plasma values were also elevated in patients with OAC vs NE $(P<0.001)$ or $B O(P=0.015)$. High MIC-1/GDF15 plasma levels $\left(\geqslant 1140 \mathrm{pg} \mathrm{ml}^{-1}\right)$ were an independent predictor of poor survival for patients with $\mathrm{OAC}(\mathrm{HR} 3.87,95 \% \mathrm{Cl} 1.01-14.75 ; P=0.047)$.

Conclusions: Plasma and tissue levels of MIC-1/GDF15 are significantly elevated in patients with BO, LGD and OAC. Plasma MIC-1/GDF15 may have value in diagnosis and monitoring of Barrett's disease.

Barrett's oesophagus (BO) is an acquired condition in which the normal squamous lining of the distal oesophagus is replaced by a specialised intestinal metaplastic (IM) columnar epithelium (Phillips et al, 2011). Barrett's oesophagus is found in $\sim 6-12 \%$ of all upper gastrointestinal endoscopies (Ford et al, 2005) and in an estimated $1.6 \%$ of individuals in Western populations. Known risk factors for $\mathrm{BO}$ include gastroesophageal reflux disease (GERD), male sex, age over 50 years, Caucasian ethnicity, obesity (especially with a central/visceral fat distribution) and smoking (Cook et al, 2012; Fitzgerald et al, 2014).
Barrett's oesophagus is a multistage disease in which a minority of patients progress from IM through the stages of low-grade dysplasia (LGD) to high-grade dysplasia (HGD) and to oesophageal adenocarcinoma (OAC; Clemons et al, 2013). Recent population-based data indicate that patients with $\mathrm{BO}$ without dysplasia have an $\sim 0.5 \%$ annual risk of progression from BO to OAC (Hvid-Jensen et al, 2011; Desai et al, 2012). This risk is higher for patients with HGD, who may have a $6 \%$ or higher annual risk of progressing to cancer (Spechler, 2013). Oesophageal adenocarcinoma is a highly fatal cancer, which has

*Correspondence: Professor RV Lord; E-mail: rvlord@stvincents.com.au

Received 17 December 2014; revised 5 February 2015; accepted 16 February 2015; published online 17 March 2015 
increased six-fold in incidence over the past three decades (Eheman et al, 2012).

Recent data indicate that endoscopic surveillance may correlate with earlier stage diagnosis and improved survival from cancer (Bhat et al, 2014). For this reason, guidelines on the management of BO (Spechler et al, 2011; Fitzgerald et al, 2014) generally recommend endoscopic surveillance with histopathological assessment of dysplasia in four-quadrant random biopsies taken every $2 \mathrm{~cm}$, in addition to targeted biopsies taken from macroscopically visible lesions (so-called Seattle protocol).

There are significant problems with the endoscopic surveillance of patients with $\mathrm{BO}$, including sampling error and variation in the histopathological interpretation of the degree of dysplasia (Reid et al, 1988; Lao-Sirieix and Fitzgerald, 2012). In addition, OAC can also develop in the interval between surveillance endoscopies (Spechler, 2007). Further, only 5-7\% of patients presenting with OAC have a previous diagnosis of BO (Dulai et al, 2002; Bhat et al, 2014).

These deficiencies in current management have stimulated a search for biomarkers to improve both the early detection of OAC and the identification of patients with $\mathrm{BO}$ who are at high risk of progressing OAC. So far no biomarkers have proven adequate for routine clinical practice (Varghese et al, 2012; Fitzgerald et al, 2014). A blood biomarker would have several advantages over the current subjective histologic interpretation of endoscopic tissue biopsies, including being less invasive and safer, less expensive and potentially applicable for at-risk population screening.

Macrophage inhibitory cytokine 1 (MIC-1, also known as growth differentiation factor $15, \mathrm{GDF} 15)$, is a divergent member of the transforming growth factor- $\beta$ (TGF- $\beta$ ) superfamily, which is not highly expressed under normal conditions, other than in the placenta (Bootcov et al, 1997; Fairlie et al, 1999). Its expression is increased by injury, inflammation or malignancy and it is involved in the pathogenesis of a number of disease including cancer and cardiovascular diseases (Breit et al, 2011).

Macrophage inhibitory cytokine 1 /growth differentiation factor 15 expression is increased in most cancers including those of the prostate, colon, ovary and breast (Welsh et al, 2003; de Wit et al, 2005), and various cancer cell lines are known to secrete large amounts of MIC-1/GDF15 (Bauskin et al, 2006; Unsicker et al, 2013). In many cancers, MIC-1/GDF15 serum levels are associated with histopathological cancer grade, stage and extent of disease, and have been reported as predictors of disease progression in prostate, ovary and colorectal cancer (Bauskin et al, 2006). Macrophage inhibitory cytokine 1 /growth differentiation factor 15 may also have a role as a clinical biomarker in multiple myeloma, oral squamous cancer and bladder cancer (Brown et al, 2003, 2006; Costa et al, 2010; Wallin et al, 2011; Brown et al, 2012; Corre et al, 2012). Serum levels of MIC-1/GDF15 are reported to increase during the progression of colorectal cancer (Brown et al, 2003) and serum MIC-1/GDF15 measurement is a validated prospective biomarker of the presence of colorectal polyps and cancer, indicating that it has potential as a screening tool in these diseases (Brown et al, 2012).

The above data suggest that MIC-1/GDF15 may be useful in the management of $\mathrm{BO}$ and OAC. We investigated MIC-1/GDF15 plasma and tissue levels in patients with different stages of BO to assess the potential of MIC-1/GDF15 quantification as a biomarker for diagnosis, for prediction of progression in patients with $\mathrm{BO}$, as well as for diagnosis and prognosis in patients with OAC.

\section{MATERIALS AND METHODS}

Study design, study population and specimen collection. We performed a retrospective diagnostic case-control analysis to examine the associations between (a) MIC-1/GDF15 tissue mRNA expression and normal oesophagus (NE), BO, LGD and OAC; (b) MIC-1/GDF15 plasma protein levels and NE, BO, LGD and $\mathrm{OAC}$; and (c) to test the association between MIC-1/GDF15 plasma levels and overall survival in patients with OAC. An analysis of the performance of MIC-1/GDF15 tissue and plasma levels to distinguish between NE, BO, LGD and OAC was also conducted.

The NE, BO and LGD tissues and blood samples were collected at endoscopies performed at St Vincent's Hospital, Sydney, Australia. These were obtained from patients prospectively enroled in an Australia-wide research collaboration entitled PROBE-NET: Progression of Barrett's Esophagus to Esophageal Adenocarcinoma Network. The OAC specimens were either obtained from patients at St Vincent's Hospital or from patients who had been enroled in the population-based case-control Australian Cancer Study through the QIMR Berghofer Medical Research Institute (QIMRB; Whiteman et al, 2008). All tissues were formalin fixed and paraffin embedded. The pathological diagnoses were established by pathologists at the respective host institutions. Sections from tissue blocks for mRNA extraction were chosen after reviewing the histopathologic reports and haematoxylin and eosin (H\&E) stained slides to confirm the presence of the correct diagnoses. Barrett's oesophagus was diagnosed when there was any length of columnar mucosa in the tubular oesophagus, with IM containing goblet cells on histopathological examination.

Patient plasma samples were collected at study recruitment, centrifuged at $1800 \mathrm{~g}$, and the resultant plasma stored at $-80^{\circ} \mathrm{C}$ until further use. For the analysis of plasma MIC-1/GDF15 levels as a prognostic marker for OAC survival, we used pretreatment samples from an independent cohort of 23 patients with OAC from the Australian Cancer Study (Whiteman et al, 2008) and 7 patients treated at St Vincent's Hospital, Sydney. All subjects were treated by oesophagectomy with curative intent and received no preoperative chemotherapy or radiotherapy. Only patients with complete clinicopathological and follow-up data $(n=27)$ were included in the survival analysis.

Institutional review board approval for this study was obtained at all collaborating institutions and all patients provided written informed consent.

RNA isolation. All tissues processed were cut from formalinfixed, paraffin-embedded tissue blocks. Two $7-\mu \mathrm{m}$ sections were cut for RNA extraction, which was performed using the Qiagen FFPE RNeasy kit, (cat \# 74404, Qiagen, Valencia, CA, USA) following the manufacturer's protocol. Satisfactory RNA yield and quality were confirmed using the BioSpec-nano spectrophotometer (Shimadzu Scientific Instruments, Sydney, Australia).

Multiplexed tandem PCR. Multiplexed tandem PCR (MT-PCR) was used to quantitate the mRNA expression levels of MIC-1/ GDF15 and a reference gene, NONO ('non-POU domaincontaining, octamer-binding (NONO), transcript variant 2'; NM_007363), using the Rotor-Gene 6000 real-time quantitative PCR system (Corbett Life Sciences/Qiagen, Sydney, Australia), as previously described (Stanley and Szewczuk, 2005; Botelho et al, 2010). Briefly, MT-PCR is performed in two stages. In the first stage, isolated RNA is converted into cDNA and amplified using gene-specific primers ('outer' primers). In the second step, the product from stage one is used as a template for PCRs run in a 72well disc-containing single-gene primers ('inner' primers) in each well. Primers were designed using Primer 3 software modified by AusDiagnostics Pty. Ltd. (AusDiagnostics, Alexandria, New South Wales, Australia). All primer pairs spanned an intron-exon boundary and all samples were run in duplicate. Correct product size and integrity was verified on a Bioanalyzer DNA separation chip (Agilent Technologies, Forest Hill, Victoria, Australia). The relative mRNA expression values were calculated as the ratio of the 
raw MIC-1/GDF15 mRNA values to the control gene NONO, with the expression of NONO set to a fixed level (1000).

MIC-1/GDF15 enzyme-linked immunosorbent assay. Plasma MIC-1/GDF15 levels were measured using a validated sandwich enzyme immunoassay, as described previously (Moore et al, 2000; Fairlie et al, 2001; Brown et al, 2002). Briefly, mouse mAb 26G6H6 was used for antigen capture and sheep PAb 233-P was used for detection. The human MIC-1/GDF15 (hMIC-1/GDF15) plasma concentration was determined by reference to a standard curve, which was constructed using recombinant hMIC-1/GDF15. All samples were run in duplicate. To ensure reproducibility, the coefficient of variation for all readings was below $10 \%$. Assay performance was further monitored using standard diagnostic laboratory quality control procedures.

Statistical analysis. Continuous variables were compared using $t$-test statistics, Wilcoxon rank-sum test, one-way analysis of variance and the Kruskal-Wallis test where appropriate. Where necessary, $\log 2$ transformation of mRNA relative expression and plasma ELISA values was performed to achieve normal distribution for these analyses. Differences between proportions derived from categorical data were analysed using Pearson's chi-squared test or Fisher's exact test.

The area under the curve (AUC) of the receiver operator characteristic (ROC) curve and 95\% confidence interval (CI) was calculated to explore the performance of MIC-1/GDF15 tissue and plasma levels to discriminate between patient pathology groups for three distinct potential clinical uses as follows: (i) to explore the potential of MIC-1/GDF15 tissue and/or plasma measurement as a screening test for $\mathrm{OAC}$, we assessed discrimination between $\mathrm{OAC}$ vs non-OAC patients (NE, BO and LGD); (ii) to assess the potential of MIC-1/GDF15 measurement as a triage test to rule out low-risk patients who do not require further intervention or endoscopy surveillance, we assessed discrimination between NE and BO vs LGD and OAC; and (iii) to assess the performance of tissue MIC-1/GDF15 gene expression and plasma levels as a diagnostic test to identify patients at high risk of developing OAC, we assessed discrimination between OAC and its respective 'high'risk population (BO IM + LGD). For each of these potential biomarker purposes, the optimal cut point for MIC-1/GDF15 was selected by the Youden's index (Youden, 1950) to inform future validation studies and the sensitivity, specificity at this cut point was reported with $95 \% \mathrm{CI}$.

As MIC-1/GDF15 plasma values are known to correlate with nutritional status and BMI (Johnen et al, 2007; Breit et al, 2011), BMI was recorded for all patients providing plasma samples, and we performed a separate analysis for patients who were non-obese and not underweight (BMI 18.5-29.9 $\mathrm{kg} \mathrm{m}^{-2}$ ) as defined by the WHO (WHO, 2014).

The Kaplan-Meier method was used to compare survival times for patients classified by MIC-1/GDF15 cutoff levels and differences in survival times were compared using the log-rank test. A Cox proportional hazards model was used to identify independent factors associated with mortality. Only patients with complete clinicopathological and survival data were included for survival analysis $(n=27)$. Data are presented as mean (s.d.), median (interquartile range (IQR)) and OR/HR (95\% CI), where applicable. All $P$-values $<0.05$ were regarded as statistically significant. For ROC curve AUC analysis, the $P$-value indicates the probability that an observed sample AUC is found when the true AUC is 0.5 (no difference between groups). If the $P$-value is $<0.05$, it can be concluded that the AUC is statistically significantly different from 0.5 providing statistical evidence that the biomarker has the ability to distinguish between the two groups (Youden, 1950; Obuchowski, 2003).

All statistical analyses were performed using $\mathrm{R}$ Statistical Packages ( $\mathrm{R}$ Core Team, 2013) and graphing/plotting was performed in Prism (GraphPad Prism version 6.0c for Mac OS X, GraphPad Software, San Diego, California, USA).

\section{RESULTS}

Patients and tissues. Demographic data for the 138 patients included in this study are shown in Table 1. Briefly, 45 patients (33\%) who underwent clinically indicated upper endoscopy showing no BO and who had no history of GERD were included as healthy controls and provided normal squamous oesophageal tissue and baseline blood samples. Thirty-seven patients (27\%) had histologically confirmed BO with IM but no dysplasia, and 16 patients (12\%) had BO with LGD. Of the 40 patients with OAC, most had AJCC stage I-IIB disease (73\%), whereas 8 patients were stage III (20\%) and 1 was stage IV (3\%). Despite chart review the correct tumour stage could not be assessed in two patients $(5 \%)$ due to incomplete clinical data.

MIC-1/GDF15 tissue mRNA expression analysis. MIC-1/GDF15 was significantly overexpressed in BO, LGD and OAC when compared to normal squamous oesophagus (Figure 1A). Median relative mRNA expression of MIC-1/GDF15 increased 25-fold from NE to BO (44.2 to 1092.0; $P<0.001$ ), with median expression levels higher in $\mathrm{BO}-\mathrm{LGD}$ compared to $\mathrm{BO}$, although this difference was not statistically significant $(1092.0$ vs $1185 ; \quad P=0.43)$. Macrophage inhibitory cytokine 1 /growth differentiation factor 15 expression was 47 times higher in OAC compared to $\mathrm{NE}$ (2249.0 vs 44.2; $P<0.001$ ), and was also significantly higher in OAC compared to BO IM (2249 vs 1092; $P=0.039$ ).

The AUC for the discriminative performance of MIC-1/GDF15 gene expression to distinguish between $\mathrm{OAC}$ and non-OAC (NE, BO and LGD) was 0.82 (95\% CI $0.70-0.93$; $P<0.001$ ). For this analysis, the optimal cut point for relative MIC-1/GDF15 mRNA expression was 961 , which yielded a sensitivity of $88 \%$ (95\% CI $68-$ $97 \%)$ and specificity of $64 \%$ (95\% CI $44-81 \%)$ for the detection of OAC (Table 2).

The AUC for the discriminative performance of MIC-1/GDF15 to rule out LGD or OAC was 0.86 (95\% CI $0.73-0.96 ; P<0.001$ ). For this analysis, the optimal cut point for relative MIC-1/GDF15 mRNA expression was 720, which yielded a sensitivity of $94 \%$ (95\% CI $79-99 \%)$ and specificity of $71 \%$ (95\% CI $48-89 \%$; Table 2). This result indicates that if MIC-1/GDF15 mRNA expression values are low, the presence of OAC and/or dysplastic Barrett's disease can be ruled out with a $6 \%$ false-negative rate (95\% CI 1-21\%).

The diagnostic performance of tissue MIC-1/GDF15 gene expression to distinguish between $\mathrm{OAC}$ and the at-risk population (BO IM, LGD) was AUC 0.70 (95\% CI 0.51-0.88; Figure 1B) with a sensitivity of $63 \%$ (95\% CI $41-81 \%$ ) and specificity of $77 \%$ (95\% CI $50-93 \%$ ) at the optimal cut point of 1768 (Table 2).

MIC-1/GDF15 plasma analysis. Median MIC-1/GDF15 plasma values were significantly higher in patients with OAC compared to healthy controls $\left(1018 v s 606 \mathrm{pg} \mathrm{ml}^{-1} ; P<0.001\right)$, patients with $\mathrm{BO}$ (1018 vs $\left.783 \mathrm{pg} \mathrm{ml}^{-1} ; P=0.015\right)$ and patients with BO with LGD (735 $\mathrm{pg} \mathrm{ml}^{-1}, P=0.027$; Figure $2 \mathrm{~A}$ ).

The discriminative performance of plasma MIC-1/GDF15 levels to distinguish between $\mathrm{NE}, \mathrm{BO}, \mathrm{LGD}$ and $\mathrm{OAC}$ is shown in Figure $2 \mathrm{~B}$ and Table 2. For example, for use as a screening test, the AUC of plasma MIC-1/GDF15 levels for the detection of OAC vs non-malignant oesophageal findings (NE, BO and LGD) was 0.75 (95\% CI $0.65-0.85 ; P<0.001$ ) with MIC-1/GDF15 plasma levels above an optimal cut point of $811 \mathrm{pg} \mathrm{ml}^{-1}$ yielding a sensitivity of $83 \%$ (95\% CI 65-94\%) and specificity of 62\% (95\% CI 50-74\%) for the detection of OAC. However, the AUC for MIC-1/GDF15 plasma measurements as a triage test to rule out LGD or OAC did 
Table 1. Clinical and pathologic characteristics of included patients

\begin{tabular}{|c|c|c|c|c|c|c|}
\hline & \multicolumn{2}{|c|}{ All $(n=138)$} & \multicolumn{2}{|c|}{ mRNA analysis $(n=53)$} & \multicolumn{2}{|c|}{ Plasma analysis $(n=99)$} \\
\hline & Number & $\%$ & Number & $\%$ & Number & $\%$ \\
\hline \multicolumn{7}{|l|}{ Gender } \\
\hline Males & 102 & 74 & 42 & 79 & 73 & 74 \\
\hline Females & 36 & 26 & 11 & 21 & 26 & 26 \\
\hline Median age, years (range) & 60 & $51-68$ & 63 & $55-74$ & 61 & $51-68$ \\
\hline \multicolumn{7}{|l|}{ Diagnosis } \\
\hline Normal oesophagus & 45 & 33 & 12 & 23 & 33 & 33 \\
\hline Barrett's oesophagus IM & 37 & 27 & 10 & 19 & 27 & 27 \\
\hline Barrett's oesophagus with dysplasia & 16 & 12 & 7 & 13 & 9 & 9 \\
\hline Oesophageal adenocarcinoma & 40 & 29 & 24 & 45 & 30 & 30 \\
\hline \multicolumn{7}{|l|}{ TNM (7th edition) } \\
\hline T1-2 & 31 & 78 & 22 & 92 & 23 & 77 \\
\hline T3-4 & 7 & 18 & - & - & 7 & 23 \\
\hline $\mathrm{N} 1-3$ & 11 & 8 & 3 & 13 & 10 & 33 \\
\hline$M+$ & 1 & 3 & - & - & 1 & 3 \\
\hline Unknown $\mathrm{T}, \mathrm{N}$ or $\mathrm{M}$ & 2 & 5 & 2 & 8 & 0 & - \\
\hline \multicolumn{7}{|l|}{ Tumour stage (AJCC 7th edition) } \\
\hline IA-B & 14 & 35 & 9 & 38 & 11 & 37 \\
\hline$\| A$ & 13 & 33 & 10 & 42 & 9 & 30 \\
\hline IIB & 2 & 5 & 2 & 8 & 1 & 3 \\
\hline IIIA-C & 8 & 20 & 1 & 4 & 8 & 27 \\
\hline IV & 1 & 3 & - & - & 1 & 3 \\
\hline Unknown stage & 2 & 5 & 2 & 8 & 0 & - \\
\hline Median survival, months (range) & 38 & $18-51$ & 34 & $18-48$ & 43 & $23-56$ \\
\hline
\end{tabular}

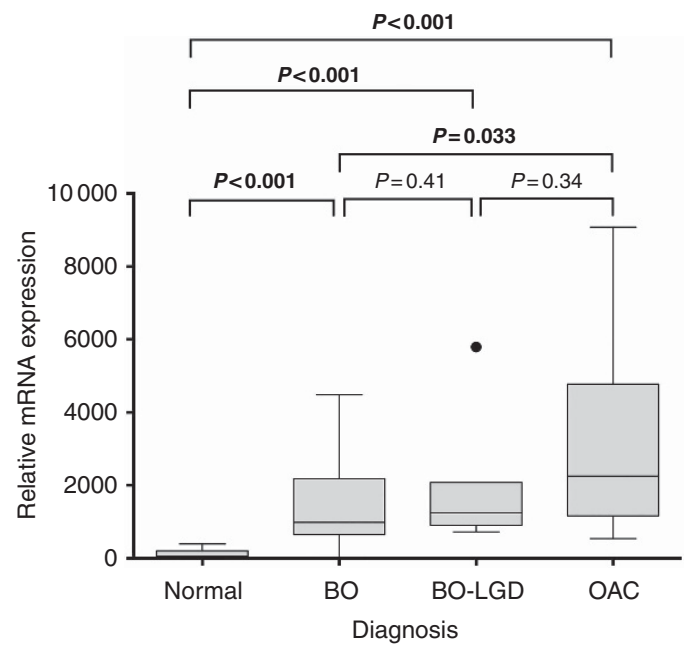

Figure 1. Boxplot of tissue MIC-1/GDF15 mRNA expression analysis by pathology diagnosis. Raw relative mRNA expression values are presented. Differences in relative gene expression values were calculated using Student's t-test following log2 transformation. Bold values indicates that these are statistically significant. Dot indicates outlier as is convention for presenting boxplot data.

not indicate potential for discriminating between patient groups (data not shown).

In patients who were non-obese and not underweight (BMI $18.5-29.9 \mathrm{~kg} \mathrm{~m}^{-2}$ ) as defined by the WHO (WHO, 2014), median MIC-1/GDF15 plasma levels were slightly lower for all patient groups except for those patients with $\mathrm{OAC}$, where median plasma levels were in a similar range $\left(1040.5 \mathrm{pg} \mathrm{ml}^{-1} ; P=0.85\right)$. Figure $2 \mathrm{C}$ summarises the findings of the plasma analysis when corrected for BMI.

The discriminative performance of plasma MIC-1/GDF15 levels corrected for BMI to distinguish between NE, BO, LGD and OAC is shown in Figure 2D and Table 2. Briefly, non-obese patients with a MIC-1/GDF15 plasma value above the optimal cut point of $811 \mathrm{pg} \mathrm{ml}^{-1}$ were approximately four times more likely to have a malignant oesophageal finding than those with lower MIC-1/ GDF15 plasma levels (AUC 0.85 (95\% CI 0.76-0.95), sensitivity 84\% (95\% CI 64-95\%) and specificity 80\% (95\% CI 65-90\%)).

MIC-1/GDF15 plasma levels and overall survival in OAC. Two patients were excluded from the survival analysis due to incomplete clinicopathological data. Patients were grouped into AJCC stages 1 and 2 in one group and stages 3 and 4 in another group.

There were no significant associations between MIC-1/GDF15 plasma levels and any of the following known prognostic factors: histopathological grade, T-stage, positive nodal status, higher tumour stage (data not shown).

There was a non-significant trend towards worse overall survival in patients with OAC and elevated levels of MIC-1/GDF15 $\left(\geqslant 1140 \mathrm{pg} \mathrm{ml}^{-1}\right.$ (optimal cut point determined by ROC curve analysis); 47.5 vs 33.0 months, $P=0.063$; Figure 3). However, in a multivariable Cox proportional hazards model including the independent variables age, BMI, overall tumour stage and plasma MIC-1/GDF15 values $\geqslant 1140 \mathrm{pg} \mathrm{ml}^{-1}$, both elevated plasma MIC-1/GDF15 levels (HR 3.87, 95\% CI 1.01-14.75; $P=0.048$ ) and worse tumour stages (HR 13.85, 95\% CI 2.31-83.23, $P=0.004$ ) were significant independent prognostic markers for mortality (Table 3).

\section{DISCUSSION}

In this novel study, we found evidence for an association between MIC-1/GDF15 tissue and plasma levels in patients with $\mathrm{BO}$ and OAC. This suggests that MIC-1/GDF15 could be evaluated further for its potential as a biomarker in this disease, with our results indicating a greater biomarker potential for measuring MIC-1/ GDF15 in blood rather than tissues. A non-tissue, non-endoscopic biomarker or biomarker panel detectable in blood would offer a 
Table 2. Discriminative performance of plasma MIC-1/GDF15 in predicting the presence of oesophageal pathologies

\begin{tabular}{|c|c|c|c|c|c|c|}
\hline & Youden index ${ }^{a}$ & Cutoff point ${ }^{a}$ & $\operatorname{AUC}(95 \% \mathrm{Cl})$ & Sensitivity $(95 \% \mathrm{Cl})$ & Specificity $(95 \% \mathrm{Cl})$ & $P$-value ${ }^{b}$ \\
\hline \multicolumn{7}{|l|}{ Tissue mRNA $(n=54)$} \\
\hline Non-malignant vs OAC & 0.52 & 961 & $0.82(0.70-0.93)$ & $0.88(0.68-0.97)$ & $0.64(0.44-0.81)$ & 0.001 \\
\hline $\mathrm{NE}+\mathrm{BO}$ vs LGD + OAC & 0.65 & 720 & $0.86(0.73-0.96)$ & $0.94(0.79-0.99)$ & $0.71(0.48-0.89)$ & $<0.001$ \\
\hline $\mathrm{BO}+\mathrm{LGD}$ vs OAC & 0.39 & 1768 & $0.70(0.51-0.88)$ & $0.63(0.41-0.81)$ & $0.77(0.50-0.93)$ & 0.03 \\
\hline \multicolumn{7}{|c|}{ Plasma ELISA for all patients $(n=99)$} \\
\hline Non-malignant vs OAC & 0.46 & 811 & $0.75(0.65-0.85)$ & $0.83(0.65-0.94)$ & $0.62(0.50-0.74)$ & $<0.001$ \\
\hline $\mathrm{NE}$ vs $\mathrm{BO}+\mathrm{LGD}+\mathrm{OAC}$ & 0.35 & 705 & $0.70(0.58-0.82)$ & $0.74(0.62-0.84)$ & $0.61(0.42-0.77)$ & 0.001 \\
\hline $\mathrm{BO}+\mathrm{LGD}$ vs OAC & 0.39 & 811 & $0.72(0.56-0.84)$ & $0.83(0.65-0.94)$ & $0.56(0.38-0.72)$ & 0.003 \\
\hline \multicolumn{7}{|c|}{ Plasma ELISA for patients with a BMI of $18.5-29.9 \mathrm{~kg} \mathrm{~m}^{-2}(n=69)$} \\
\hline Non-malignant vs OAC & 0.63 & 811 & $0.85(0.76-0.95)$ & $0.84(0.64-0.95)$ & $0.80(0.65-0.90)$ & $<0.001$ \\
\hline $\mathrm{NE}$ vs $\mathrm{BO}+\mathrm{LGD}+\mathrm{OAC}$ & 0.44 & 705 & $0.77(0.65-0.90)$ & $0.69(0.55-0.82)$ & $0.75(0.51-0.91)$ & $<0.001$ \\
\hline $\mathrm{BO}+\mathrm{LGD}$ vs OAC & 0.59 & 836 & $0.83(0.71-0.95)$ & $0.76(0.55-0.91)$ & $0.83(0.63-0.95)$ & $<0.001$ \\
\hline \multicolumn{7}{|c|}{ 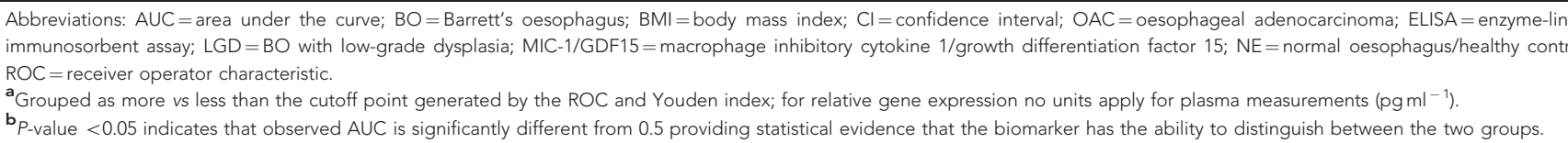 } \\
\hline
\end{tabular}

MIC-1/GDF15 plasma analysis in all patients
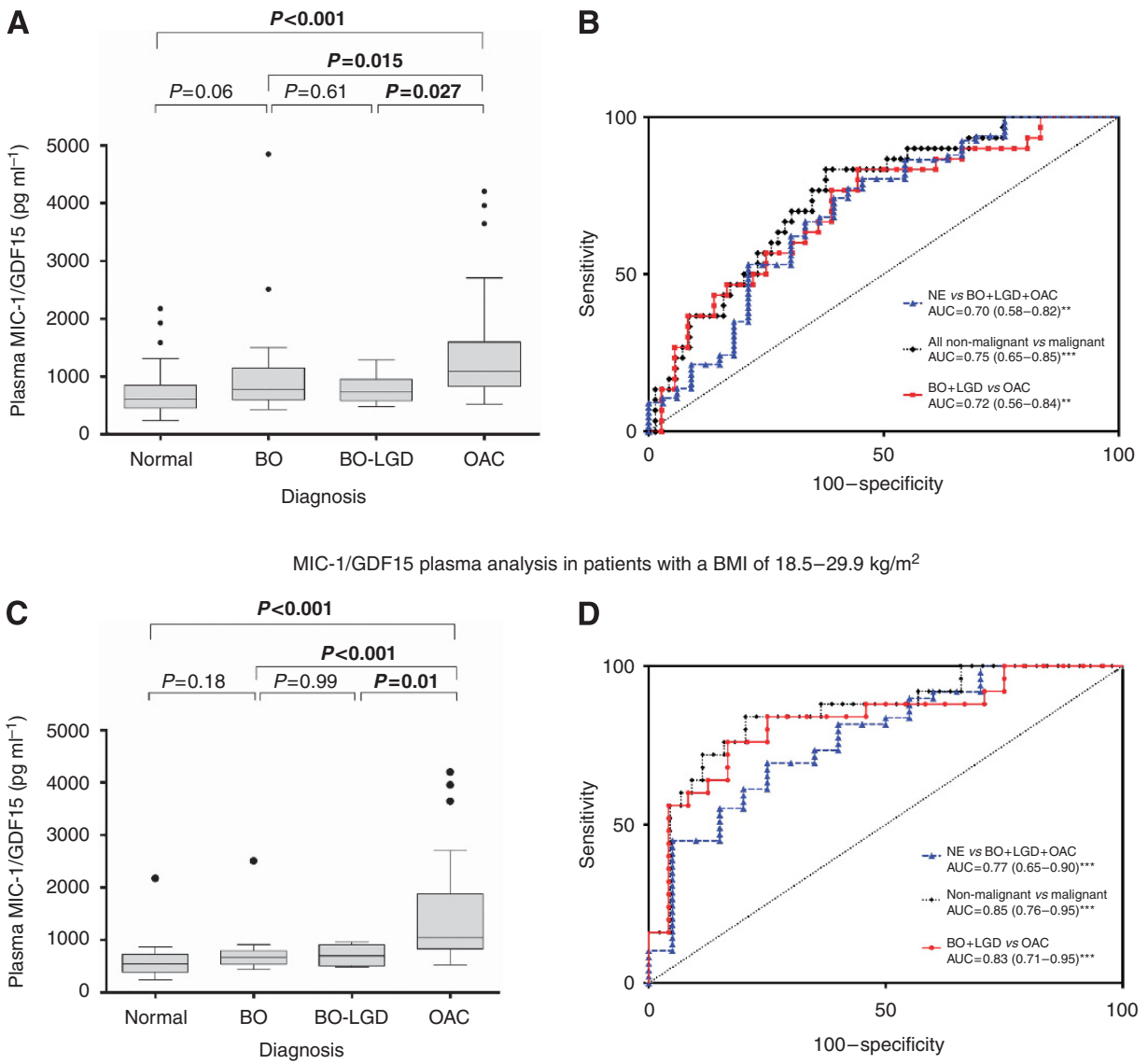

Figure 2. Boxplots of MIC-1/GDF15 plasma levels by pathology diagnosis and corresponding receiver operator characteristic (ROC) curves for performance analysis of tissue MIC-1/GDF15 plasma levels to discriminate patient groups. (A and B) Show the analysis of the whole study cohort, whereas ( $\mathbf{C}$ and $\mathbf{D}$ ) depict the findings in the non-obese, non-underweight (as categorised by the WHO) patient population. Differences in plasma values were calculated using Student's t-test following log2 transformation. Data are presented untransformed as pg ml ${ }^{-1}$. Bold values indicates that these are statistically significant. Dot indicates outlier as is convention for presenting boxplot data. ${ }^{\star \star} P<0.01 ;{ }^{\star \star \star} P<0.001$.

major advantage if it could replace the need for pathology classification of dysplasia. Although the presence of dysplasia in $\mathrm{BO}$ detected by histopathological examination of tissue specimens is the most informative current predictor of risk of progression to
$\mathrm{OAC}$, it is not a reliable tests as shown by the disturbing lack of agreement between pathologists and their interpretation of presence or severity of dysplasia (Reid et al, 1988; Spechler, 2007). Histopathological examination of the primary tumour and 
resected lymph nodes along with radiologic tests is also the current basis of staging patients with $\mathrm{OAC}$ and determining prognosis, but similarly has limited accuracy. For example, $\sim 50 \%$ of patients assessed as having no lymph node involvement at diagnosis, and thus a good prognosis, will still die of their disease by 10 years (Rice et al, 2003). Identifying predictive and prognostic biomarkers for $\mathrm{BO}$ and $\mathrm{OAC}$ is thus crucial to improve clinical care.

Our evaluation of MIC-1/GDF15 plasma quantification as a diagnostic test for OAC found that patients with high MIC-1/ GDF15 plasma levels who were neither underweight nor obese were more than four times more likely to have OAC. This likelihood decreased by two-fold if obese or underweight patients were included in the analysis. This reduction may be explained by the confounding effect of the known relationship of MIC-1/GDF15 blood levels and BMI (Johnen et al, 2007; Breit et al, 2011). This finding addresses a potential limitation of the clinical applicability of plasma MIC-1/GDF15 analysis for the diagnosis and monitoring of patients with Barrett's disease, as patients with $\mathrm{BO}$ usually have higher BMI and increased waist circumference (Kubo et al, 2013). Conversely, however, as elevated MIC-1/GDF15 serum levels are known to be associated with tumour-induced weight loss (Wakchoure et al, 2009; Tsai et al, 2012), patients with noted weight loss (despite the lack of dysphagia/reduced food intake) and elevated plasma MIC-1 levels may identify those at highest risk of bearing an oesophageal malignancy.

Others have shown the potential clinical use for MIC-1/GDF15 in blood for the diagnosis and/or monitoring of pancreatic, prostate, colon and thyroid cancers, especially when MIC-1/ GDF15 is combined with other markers, as we anticipate would also be the case with OAC (Koopmann et al, 2004; Brown et al, 2006). In pancreatic cancer, for example, combining MIC-1/ GDF15 serum levels with CA19-9 significantly improved the

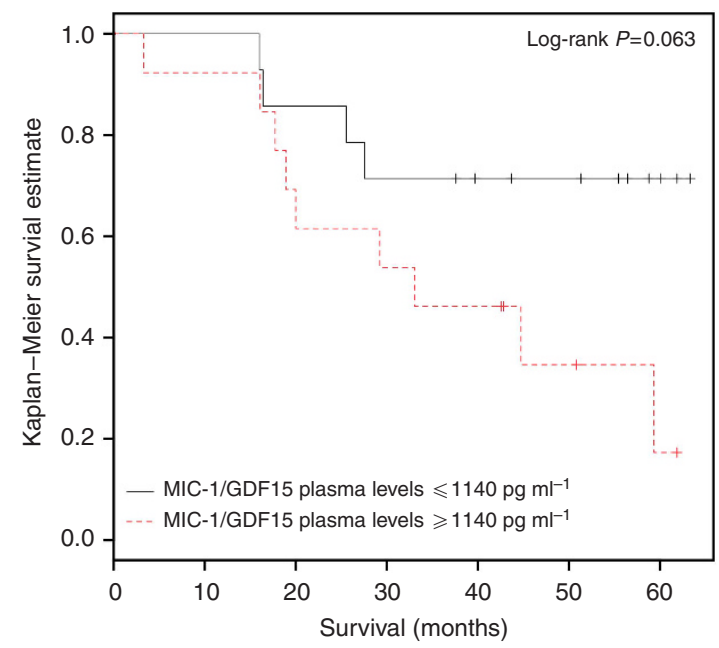

Figure 3. Survival of OAC patients stratified by MIC-1/GDF15 plasma levels $\geqslant 1140 \mathrm{pg} \mathrm{ml}^{-1}$ (as determined by ROC curve analysis). diagnosis of pancreatic cancer leading to a sensitivity of $70 \%$ and specificity of $85 \%$ (Koopmann et al, 2004). In prostate cancer, the combination of serum MIC-1/GDF15 levels with prostate-specific antigen significantly improved the overall diagnostic specificity and shows great potential for monitoring of disease progression (Brown et al, 2006).

In this study, we also found that elevated MIC-1/GDF15 plasma levels were an independent prognostic marker for reduced overall survival in patients, although the reliability of this finding is diminished by the small number of patients in this section $(n=27)$. This finding was significant when MIC-1/GDF15 was included in a multivariable Cox proportional hazards model, which was adjusted for age, tumour stage and BMI. The patients in this study were treated by oesophagectomy alone in all but one case. Because no patient received neoadjuvant chemotherapy or radiotherapy, our findings are unlikely to be explained by variations in treatment or the effect of treatment on tumour biology.

Studies of patients with other malignancies have suggested that MIC-1/GDF15 is a marker of adverse prognosis as its blood levels increased with increasing histopathological grade, invasiveness and metastasis (Mimeault and Batra, 2010; Breit et al, 2011). However, in this study, we did not find a significant difference in plasma MIC-1/GDF15 levels between patients with lower $v s$ higher stages of OAC. We believe this is most likely due to the limited number of patients with more advanced stages of the disease. Further studies are required to help resolve whether blood levels of MIC-1/GDF15 can help in OAC staging. A blood marker that can identify patients with locally limited but perhaps occult disseminated disease would potentially allow early allocation to more aggressive treatment strategies.

Our finding that elevated plasma MIC-1/GDF15 provides independent prognostic information contrasts with the only other report on MIC-1/GDF15 blood levels that included patients with OAC (Skipworth et al, 2010). In this study, patients with elevated MIC-1/GDF15 levels showed reduced survival compared to those with lower MIC-1/GDF15 levels, but MIC-1/GDF15 was not an independent prognostic indicator. However, this study also included patients with oesophageal squamous, undifferentiated and neuroendocrine carcinoma, and $52 \%$ of the included cancers were not of oesophageal origin (oesophageal junction with undefined localisation or gastric cancer) leading to a more heterogeneous study population. In contrast to Skipworth et al, 2010 however, we did not have data on systemic inflammatory markers and were therefore not able to adjust for this in our Cox regression model.

In oesophageal tissue biopsies, we found that MIC-1/GDF15 mRNA levels were associated with the presence of $\mathrm{BO}$ as well as the stage of the disease (IM, LGD and OAC). These findings indicate it may have potential to aid in conventional histopathology methods. This could be explored in future studies by comparing MIC-1/ GDF15 results with conventional methods to determine its clinical value for patient management. In particular, given the high clinical need to identify patients at risk of progression to OAC, our results suggest that it may be useful to explore tissue MIC-1/GDF15 levels

Table 3. Univariable and multivariable Cox proportional hazards model for survival $(n=27)$

\begin{tabular}{|c|c|c|c|c|c|c|}
\hline \multirow[b]{2}{*}{ Variable } & \multicolumn{3}{|c|}{ Univariable analysis } & \multicolumn{3}{|c|}{ Multivariable analysis } \\
\hline & HR & $95 \% \mathrm{Cl}$ & $P$-value & HR & $95 \% \mathrm{Cl}$ & $P$-value \\
\hline Age & 0.99 & $0.95-1.04$ & 0.82 & 1.04 & $0.98-1.11$ & 0.23 \\
\hline Body mass index & 0.96 & $0.84-1.10$ & 0.59 & 0.99 & $0.85-1.15$ & 0.88 \\
\hline High tumour stage (III/IV) & 5.85 & $1.92-17.85$ & 0.0019 & 13.86 & $2.31-83.23$ & 0.004 \\
\hline MIC-1/GDF15 plasma levels $\geqslant 1140 \mathrm{pg} \mathrm{ml}^{-1}$ & 2.91 & $0.89-9.48$ & 0.076 & 3.87 & $1.01-14.75$ & 0.048 \\
\hline
\end{tabular}


in prospective studies of $\mathrm{BO}$ patients, in contrast to the crosssectional design of the present study. It would also be useful to investigate through in vivo studies (which we have not performed), the correlation between MIC-1/GDF15 tissue and plasma levels in this disease, as in other malignancies the intracellular processing of MIC-1/GDF15 ultimately determines the relative amount of MIC$1 / \mathrm{GDF}$ that remains in the tumour microenvironment $v s$ the amount diffusing into the systemic circulation. This additive predictive value has been demonstrated in prostate cancer stromal staining, where detection of proMIC-1/GDF15 was an important independent predictor of disease relapse (Bauskin et al, 2005, 2006).

There are two possible explanations for our findings in tissues. First, the increased MIC-1/GDF15 levels in BO IM, BO-LGD and $\mathrm{OAC}$ may be linked to the inflammatory response of the oesophagus to severe GERD, as MIC-1/GDF15 is increased in response to multiple cellular stressors and following acute injury and/or inflammatory tissue changes (Fairlie et al, 1999; Welsh et al, 2003; Unsicker et al, 2013). Alternatively (or in addition) MIC-1/ GDF15 levels may also signal neoplastic progression of $\mathrm{BO}$ to OAC, which is consistent with data in colon cancer, in which MIC1/GDF15 levels increase with disease progression from normal to adenoma, carcinoma and metastatic disease (Brown et al, 2003).

There are clear limitations to our findings. First, due to the relatively small sample size of the present study, the results presented must be interpreted with caution and require confirmation in future, larger well-described Barrett's/OAC patient cohorts. Second, tissue specimen sampling error may occur, a general problem in all studies using endoscopic biopsy specimens from patients with Barrett's disease (Lao-Sirieix and Fitzgerald, 2012). By reviewing the histology of all specimens used prior to RNA extraction, we attempted to minimise non-uniformity in the tissue specimens used. Third, our estimates of sensitivity and specificity are drawn from a selective sample of patients presenting for endoscopy and therefore need to be interpreted with caution due to the potential for spectrum bias, which is associated with overestimates of test accuracy (Pepe et al, 2008). Lastly, MIC-1/GDF15 plasma levels are known to be influenced by the use of nonsteroidal anti-inflammatory drugs (NSAIDs; Brown et al, 2012), which in turn have been shown to influence oesophageal adenocarcinogenesis and the prognosis of patients affected by this cancer (Buskens et al, 2002). We did not have complete data on patients' NSAID use and thus were not able to correct for this possible confounding factor.

In conclusion, however, this study provides evidence to suggest that blood MIC-1/GDF15 measurements may have a clinical role for diagnosis and monitoring of Barrett's disease spectrum. These findings need to be confirmed in larger prospective studies, in particular studies including serial MIC-1/GDF15 blood measurements in patients with different stages of $\mathrm{BO}$ to determine how dynamic changes in MIC-1/GDF15 levels may be used to inform patient management. Further, for patients already affected by OAC, blood levels of MIC-1/GDF15 may help provide additional prognostic information.

\section{ACKNOWLEDGEMENTS}

This work was supported by the National Health and Medical Research Council (NHMRC 1040947), Cancer Council New South Wales (SRP 08-04 and RG 13-03) and St Vincent's Clinic Foundation, Sydney. OMF was supported by the Swiss Cancer League (BIL KLS-3133-02-2013). DF was supported by the Swedish Society of Medicine, the Maggie Stephens Foundation and the Sparre Foundation. DAB is a recipient of a NHMRC Career Development Fellowship.

\section{CONFLICT OF INTEREST}

$\mathrm{DAB}$ and $\mathrm{SNB}$ are named inventors on patents owned by $\mathrm{St}$ Vincent's Hospital that pertain to the clinical use of MIC-1/GDF15 diagnostic assay and modulatory therapy. The funders had no role in study design, data collection and analysis, decision to publish or preparation of the manuscript.

\section{REFERENCES}

Bauskin AR, Brown DA, Junankar S, Rasiah KK, Eggleton S, Hunter M, Liu T, Smith D, Kuffner T, Pankhurst GJ, Johnen H, Russell PJ, Barret W, Stricker PD, Grygiel JJ, Kench JG, Henshall SM, Sutherland RL, Breit SN (2005) The propeptide mediates formation of stromal stores of PROMIC-1: role in determining prostate cancer outcome. Cancer Res 65: 2330-2336.

Bauskin AR, Brown DA, Kuffner T, Johnen H, Luo XW, Hunter M, Breit SN (2006) Role of macrophage inhibitory cytokine-1 in tumorigenesis and diagnosis of cancer. Cancer Res 66: 4983-4986.

Bhat SK, McManus DT, Coleman HG, Johnston BT, Cardwell CR, McMenamin U, Bannon F, Hicks B, Kennedy G, Gavin AT, Murray LJ (2014) Oesophageal adenocarcinoma and prior diagnosis of Barrett's oesophagus: a population-based study. Gut 64: 20-25.

Bootcov MR, Bauskin AR, Valenzuela SM, Moore AG, Bansal M, He XY, Zhang HP, Donnellan M, Mahler S, Pryor K, Walsh BJ, Nicholson RC, Fairlie WD, Por SB, Robbins JM, Breit SN (1997) MIC-1, a novel macrophage inhibitory cytokine, is a divergent member of the TGF-beta superfamily. Proc Natl Acad Sci USA 94: 11514-11519.

Botelho NK, Schneiders FI, Lord SJ, Freeman AK, Tyagi S, Nancarrow DJ, Hayward NK, Whiteman DC, Lord RV (2010) Gene expression alterations in formalin-fixed, paraffin-embedded Barrett esophagus and esophageal adenocarcinoma tissues. Cancer Biol Ther 10: $172-179$.

Breit SN, Johnen H, Cook AD, Tsai VW, Mohammad MG, Kuffner T, Zhang HP, Marquis CP, Jiang L, Lockwood G, Lee-Ng M, Husaini Y, Wu L, Hamilton JA, Brown DA (2011) The TGF-beta superfamily cytokine, MIC-1/GDF15: a pleotrophic cytokine with roles in inflammation, cancer and metabolism. Growth Factors 29: 187-195.

Brown DA, Bauskin AR, Fairlie WD, Smith MD, Liu T, Xu N, Breit SN (2002) Antibody-based approach to high-volume genotyping for MIC-1 polymorphism. Biotechniques 33: 118-120, 122, 124 passim.

Brown DA, Hance KW, Rogers CJ, Sansbury LB, Albert PS, Murphy G, Laiyemo AO, Wang Z, Cross AJ, Schatzkin A, Danta M, Srasuebkul P, Amin J, Law M, Breit SN, Lanza E (2012) Serum macrophage inhibitory cytokine-1 (MIC-1/GDF15): a potential screening tool for the prevention of colon cancer? Cancer Epidemiol Biomarkers Prev 21: 337-346.

Brown DA, Stephan C, Ward RL, Law M, Hunter M, Bauskin AR, Amin J, Jung K, Diamandis EP, Hampton GM, Russell PJ, Giles GG, Breit SN (2006) Measurement of serum levels of macrophage inhibitory cytokine 1 combined with prostate-specific antigen improves prostate cancer diagnosis. Clin Cancer Res 12: 89-96.

Brown DA, Ward RL, Buckhaults P, Liu T, Romans KE, Hawkins NJ, Bauskin AR, Kinzler KW, Vogelstein B, Breit SN (2003) MIC-1 serum level and genotype: associations with progress and prognosis of colorectal carcinoma. Clin Cancer Res 9: 2642-2650.

Buskens CJ, Van Rees BP, Sivula A, Reitsma JB, Haglund C, Bosma PJ, Offerhaus GJ, Van Lanschot JJ, Ristimäki A (2002) Prognostic significance of elevated cyclooxygenase 2 expression in patients with adenocarcinoma of the esophagus. Gastroenterology 122: 1800-1807.

Clemons NJ, Phillips WA, Lord RV (2013) Signaling pathways in the molecular pathogenesis of adenocarcinomas of the esophagus and gastresophageal junction. Cancer Biol Ther 14: 782-795.

Cook MB, Shaheen NJ, Anderson LA, Giffen C, Chow WH, Vaughan TL, Whiteman DC, Corley DA (2012) Cigarette smoking increases risk of Barrett's esophagus: an analysis of the Barrett's and Esophageal Adenocarcinoma Consortium. Gastroenterology 142: 744-753.

Corre J, Labat E, Espagnolle N, Hébraud B, Avet-Loiseau H, Roussel M, Huynh A, Gadelorge M, Cordelier P, Klein B, Moreau P, Facon T, Fournié JJ, Attal M, Bourin P (2012) Bioactivity and prognostic significance of 
growth differentiation factor GDF15 secreted by bone marrow mesenchymal stem cells in multiple myeloma. Cancer Res 72: 1395-1406.

Costa VL, Henrique R, Danielsen SA, Duarte-Pereira S, Eknaes M, Skotheim RI, Rodrigues A, Magalhaes JS, Oliveira J, Lothe RA, Teixeira MR, Jeronimo C, Lind GE (2010) Three epigenetic biomarkers, GDF15, TMEFF2, and VIM, accurately predict bladder cancer from DNA-based analyses of urine samples. Clin Cancer Res 16: 5842-5851.

de Wit NJ, Rijntjes J, Diepstra JH, van Kuppevelt TH, Weidle UH, Ruiter DJ, van Muijen GN (2005) Analysis of differential gene expression in human melanocytic tumour lesions by custom made oligonucleotide arrays. Br J Cancer 92: 2249-2261.

Desai TK, Krishnan K, Samala N, Singh J, Cluley J, Perla S, Howden CW (2012) The incidence of oesophageal adenocarcinoma in non-dysplastic Barrett's oesophagus: a meta-analysis. Gut 61: 970-976.

Dulai GS, Guha S, Kahn KL, Gornbein J, Weinstein WM (2002) Preoperative prevalence of Barrett's esophagus in esophageal adenocarcinoma: a systematic review. Gastroenterology 122: 26-33.

Eheman C, Henley SJ, Ballard-Barbash R, Jacobs EJ, Schymura MJ, Noone AM, Pan L, Anderson RN, Fulton JE, Kohler BA, Jemal A, Ward E, Plescia M, Ries LA, Edwards BK (2012) Annual Report to the Nation on the status of cancer, 1975-2008, featuring cancers associated with excess weight and lack of sufficient physical activity. Cancer 118: 2338-2366.

Fairlie WD, Moore AG, Bauskin AR, Russell PK, Zhang HP, Breit SN (1999) MIC-1 is a novel TGF-beta superfamily cytokine associated with macrophage activation. J Leukoc Biol 65: 2-5.

Fairlie WD, Russell PK, Wu WM, Moore AG, Zhang HP, Brown PK, Bauskin AR, Breit SN (2001) Epitope mapping of the transforming growth factor-beta superfamily protein, macrophage inhibitory cytokine-1 (MIC-1): identification of at least five distinct epitope specificities. Biochemistry 40: 65-73.

Fitzgerald RC, di Pietro M, Ragunath K, Ang Y, Kang JY, Watson P, Trudgill N, Patel P, Kaye PV, Sanders S, O’Donovan M, Bird-Lieberman E, Bhandari P, Jankowski JA, Attwood S, Parsons SL, Loft D, Lagergren J, Moayyedi P, Lyratzopoulos G, de Caestecker J. British Society of Gastroenterology (2014) British Society of Gastroenterology guidelines on the diagnosis and management of Barrett's oesophagus. Gut 63: 7-42.

Ford AC, Forman D, Reynolds PD, Cooper BT, Moayyedi P (2005) Ethnicity, gender, and socioeconomic status as risk factors for esophagitis and Barrett's esophagus. Am J Epidemiol 162: 454-460.

Hvid-Jensen F, Pedersen L, Drewes AM, Sorensen HT, Funch-Jensen P (2011) Incidence of adenocarcinoma among patients with Barrett's esophagus. $N$ Engl J Med 365: 1375-1383.

Johnen H, Lin S, Kuffner T, Brown DA, Tsai VW, Bauskin AR, Wu L, Pankhurst G, Jiang L, Junankar S, Hunter M, Fairlie WD, Lee NJ, Enriquez RF, Baldock PA, Corey E, Apple FS, Murakami MM, Lin EJ, Wang C, During MJ, Sainsbury A, Herzog H, Breit SN (2007) Tumor-induced anorexia and weight loss are mediated by the TGF-beta superfamily cytokine MIC-1. Nat Med 13: 1333-1340.

Koopmann J, Buckhaults P, Brown DA, Zahurak ML, Sato N, Fukushima N, Sokoll LJ, Chan DW, Yeo CJ, Hruban RH, Breit SN, Kinzler KW, Vogelstein B, Goggins M (2004) Serum macrophage inhibitory cytokine 1 as a marker of pancreatic and other periampullary cancers. Clin Cancer Res 10: 2386-2392.

Kubo A, Cook MB, Shaheen NJ, Vaughan TL, Whiteman DC, Murray L, Corley DA (2013) Sex-specific associations between body mass index, waist circumference and the risk of Barrett's oesophagus: a pooled analysis from the international BEACON consortium. Gut 62: 1684-1691.

Lao-Sirieix P, Fitzgerald RC (2012) Screening for oesophageal cancer. Nat Rev Clin Oncol 9: 278-287.

Mimeault M, Batra SK (2010) Divergent molecular mechanisms underlying the pleiotropic functions of macrophage inhibitory cytokine-1 in cancer. J Cell Physiol 224: 626-635.

Moore AG, Brown DA, Fairlie WD, Bauskin AR, Brown PK, Munier ML, Russell PK, Salamonsen LA, Wallace EM, Breit SN (2000) The transforming growth factor-ss superfamily cytokine macrophage inhibitory cytokine-1 is present in high concentrations in the serum of pregnant women. J Clin Endocrinol Metab 85: 4781-4788.
Obuchowski NA (2003) Receiver operating characteristic curves and their use in radiology. Radiology 229: 3-8.

Pepe MS, Feng Z, Janes H, Bossuyt PM, Potter JD (2008) Pivotal evaluation of the accuracy of a biomarker used for classification or prediction: standards for study design. J Natl Cancer Inst 100: 1432-1438.

Phillips WA, Lord RV, Nancarrow DJ, Watson DI, Whiteman DC (2011) Barrett's esophagus. J Gastroenterol Hepatol 26: 639-648.

R Core Team (2013) R: A language and environment for statistical computing. R Foundation for Statistical Computing: Vienna, Austria.

Reid BJ, Haggitt RC, Rubin CE, Roth G, Surawicz CM, Van Belle G, Lewin K, Weinstein WM, Antonioli DA, Goldman H (1988) Observer variation in the diagnosis of dysplasia in Barrett's esophagus. Hum Pathol 19: 166-178.

Rice TW, Blackstone EH, Rybicki LA, Adelstein DJ, Murthy SC, DeCamp MM, Goldblum JR (2003) Refining esophageal cancer staging. J Thorac Cardiovasc Surg 125: 1103-1113.

Skipworth RJ, Deans DA, Tan BH, Sangster K, Paterson-Brown S, Brown DA, Hunter M, Breit SN, Ross JA, Fearon KC (2010) Plasma MIC-1 correlates with systemic inflammation but is not an independent determinant of nutritional status or survival in oesophago-gastric cancer. Br J Cancer 102: 665-672.

Spechler SJ (2007) Screening and surveillance for Barrett's esophagus-an unresolved dilemma. Nat Clin Pract Gastroenterol Hepatol 4: 470-471.

Spechler SJ (2013) Barrett's esophagus: the American perspective. Dig Dis 31: $10-16$.

Spechler SJ, Sharma P, Souza RF, Inadomi JM, Shaheen NJ (2011) American Gastroenterological Association medical position statement on the management of Barrett's esophagus. Gastroenterology 140: 1084-1091.

Stanley KK, Szewczuk E (2005) Multiplexed tandem PCR: gene profiling from small amounts of RNA using SYBR Green detection. Nucleic Acids Res 33: e180.

Tsai VW, Husaini Y, Manandhar R, Lee-Ng KK, Zhang HP, Harriott K, Jiang L, Lin S, Sainsbury A, Brown DA, Breit SN (2012) Anorexia/cachexia of chronic diseases: a role for the TGF-beta family cytokine MIC-1/GDF15. J Cachexia Sarcopenia Muscle 3: 239-243.

Unsicker K, Spittau B, Krieglstein K (2013) The multiple facets of the TGF-beta family cytokine growth/differentiation factor-15/macrophage inhibitory cytokine-1. Cytokine Growth Factor Rev 24: 373-384.

Varghese S, Lao-Sirieix P, Fitzgerald RC (2012) Identification and clinical implementation of biomarkers for Barrett's esophagus. Gastroenterology 142: 435-441e2.

WHO (2014) Global Database on Body Mass Index, http://apps.who.int/bmi/ index.jsp?introPage=intro_3.html Online. http://apps.who.int/bmi/ index.jsp?introPage=intro_3.html. Accessed 5 February 2014.

Wakchoure S, Swain TM, Hentunen TA, Bauskin AR, Brown DA, Breit SN, Vuopala KS, Harris KW, Selander KS (2009) Expression of macrophage inhibitory cytokine- 1 in prostate cancer bone metastases induces osteoclast activation and weight loss. Prostate 69: 652-661.

Wallin U, Glimelius B, Jirstrom K, Darmanis S, Nong RY, Ponten F, Johansson C, Pahlman L, Birgisson H (2011) Growth differentiation factor 15: a prognostic marker for recurrence in colorectal cancer. $\mathrm{Br} \mathrm{J}$ Cancer 104: 1619-1627.

Welsh JB, Sapinoso LM, Kern SG, Brown DA, Liu T, Bauskin AR, Ward RL, Hawkins NJ, Quinn DI, Russell PJ, Sutherland RL, Breit SN, Moskaluk CA, Frierson Jr HF, Hampton GM (2003) Large-scale delineation of secreted protein biomarkers overexpressed in cancer tissue and serum. Proc Natl Acad Sci USA 100: 3410-3415.

Whiteman DC, Sadeghi S, Pandeya N, Smithers BM, Gotley DC, Bain CJ, Webb PM, Green AC. Australian Cancer Study (2008) Combined effects of obesity, acid reflux and smoking on the risk of adenocarcinomas of the oesophagus. Gut 57: 173-180.

Youden WJ (1950) Index for rating diagnostic tests. Cancer 3: 32-35.

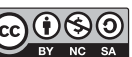

This work is licensed under the Creative Commons Attribution-Non-Commercial-Share Alike 4.0 International License. To view a copy of this license, visit http:// creativecommons.org/licenses/by-nc-sa/4.0/ 